\title{
Camera-trap assisted monitoring of presence and ecology of the hazel dormouse
}

\author{
Kamerabasiertes Monitoring der Präsenz und Ökologie der Haselmaus
}

\author{
Nina Villing, Lena Horst \\ nina@villing.de, L.horst@live.de
}

\section{Schlüsselbegriffe:}

Rodentia, Haselmaus, Muscardinus avellanarius, Kamerafallen, zeitliche Aktivität, Habitat, Spezies

\section{Keywords:}

Rodentia, Muscardinus avellanarius, camera traps, temporal activity, habitat, species

\begin{abstract}
Zusammenfassung
Die Einflüsse von Habitatparametern und das Vorkommen anderer Arten auf die Haselmaus sowie die Aktivitätsphasen dieser Art wurden mit Kamerafallen und Lockmittel in isolierten Straßenrandhabitaten im Westen Schleswig-Holsteins und Osten Hamburgs untersucht. Die gemittelte Anzahl von Nächten bis zum ersten Nachweis betrug 5,88 $( \pm 4,55)$ und Individuen wurden oft nur einmal gesichtet. Ein Muster von drei nächtlichen Aktivitätsschüben konnte festgestellt werden. Anwesenheit einer großen Waldfläche und Haselsträuchern sowie die Abwesenheit von Wald- und Gelbhalsmäusen hatten einen positiven Effekt auf die Anwesenheit von Haselmäusen an den Kamerastellen.
\end{abstract}

\begin{abstract}
Influences of habitat parameters and presence of other species on hazel dormouse presence as well as the temporal patterns of this species were investigated with camera traps and bait in isolated roadside habitats in western Schleswig-Holstein and eastern Hamburg. The mean number of trapping nights to first detection of the focal species was 5.88 ( \pm 4.55$)$ and individuals often visited only once, but a pattern of three peaks of activity during the night could be discerned. Forest size and presence of hazel, as well as absence of wood mice and yellow-necked mice were detected to have a positive effect on hazel dormouse presence at the camera sites.
\end{abstract}

\section{Introduction}

The most commonly used methods to detect hazel dormice (Muscardinus avellanarius) are nest boxes/ tubes (Bright \& MacPherson 2002), searching for natural nests (Foppen et al. 2002) or for gnawed hazelnuts (Bright, Mitchell \& Morris 1994), as well as live-trapping (Berg \& Berg 1999) and track tunnels (Mills et al. 2016). Most of these survey techniques by themselves do not give insight into correlation of habitat parameters or occupation of other species on dormice or their temporal patterns. On behalf of the Stiftung Naturschutz Schleswig-Holstein and the Department of Environment and Energy Hamburg, these factors of interest for effective implementation of future conservation efforts for the declining population numbers (Bright et al. 2006; Büchner et al. 2010), were therefore investigated with the use of camera traps.

\section{Methods}

Within three zones of interest, two in Schleswig-Holstein along the motorway A24 and one in Hamburg, 85 camera sites were surveyed gradually for 14 nights each from the 7th of August 2017 until the 23rd of 


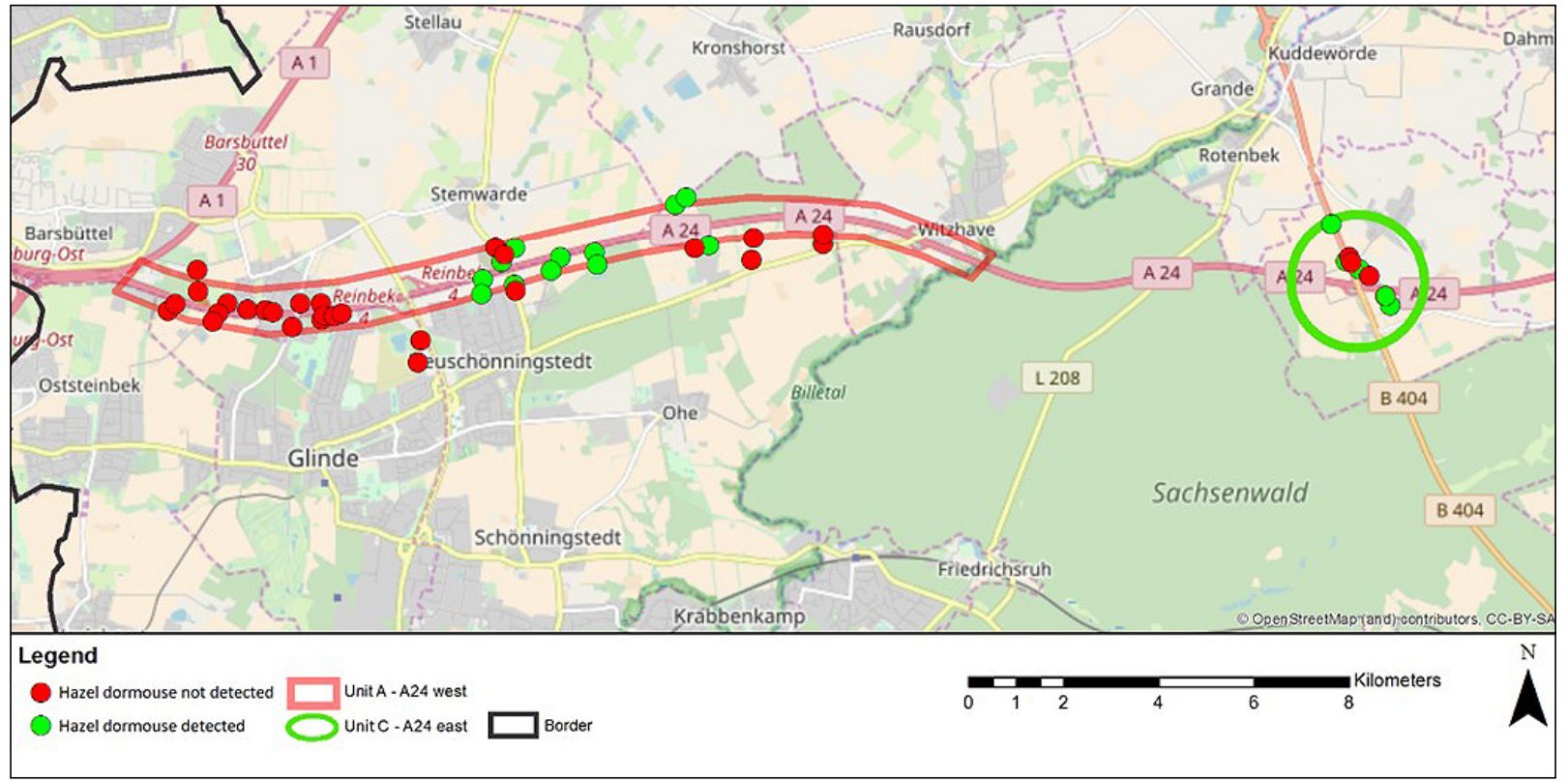

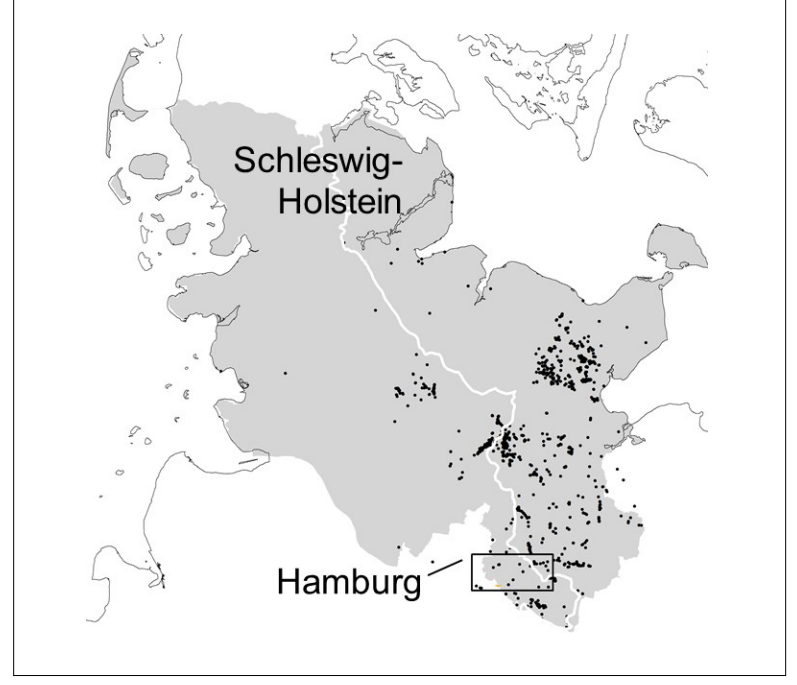

Fig. 1a (above): Study region (black rectangle) in southern Schleswig-Holstein (grey) and the southeast of Hamburg, west of the border between atlantic and continental region (white line) in relation to all historical and recent dormouse findings (black dots).

Fig.1b (at the top): location of 47 camera sites of units A (A24 west, 39 camera sites) and C (A24 east, 8 camera sites) displaying successful (green) and failed detection (red) of hazel dormouse presence. Map created using $\operatorname{ArcGIS}^{\circledR}$ software by Esri.

October 2017. The first 36 sites were surveyed a second time during the month of September to eliminate concerns of no detected dormouse presence being the result of a start too early in the season. Camera traps modified for documentation of small animals over a short distance $(20-70 \mathrm{~cm})$ and equipped with infrared flash were set to take a burst of 3 photos per detection and a delay of 30 seconds. The cameras fa- ced a wooden board baited with peanut butter and strawberry jam, around which a selection of 12 habitat parameters (Bright \& Morris 1990; Bright et al. 2006) were assessed in a $20 \mathrm{~m}$ radius.

\section{Results}

In total, 349,920 photos were taken, of which the data from the 17 sites with hazel dormouse detection were processed further. Ultimately $1.5 \%$ of the original total and $9.9 \%$ of the pictures processed recorded hazel dormice. Hazel dormouse presence was detected to the north and south along an approximately $2.68 \mathrm{~km}$ stretch of the A24 motorway (Unit A), and findings of previous years further to the east along the A24 (Unit C), around the crossing with the federal highway B404, were reconfirmed (Schulz et al. 2012; see fig. 1). No occurrences were documented in Hamburg.

The most frequently recorded species, appearing on $77.8 \%$ of the pictures on hazel dormouse sites, were the on visual records indistinguishable species of wood mice (Apodemus sylvaticus) and yellow-necked mice (A. flavicollis), collectively named Apodemus sp. (see tab. 1).

At 11 out of the 17 successful sites, hazel dormice were only recorded during one of the 14 sampling nights. At two of the successful sites, both within the same area (ca. $200 \mathrm{~m}$ apart), dormice were continu- 
ously recorded on 13 nights. The same two sites were also responsible for $95 \%$ of the total of all hazel dormouse pictures.

The mean number of trapping nights to first detection of a hazel dormouse was $5.88( \pm 4.55)$. The earliest first detection took place on the first night after installation, the latest during the 13th night.

The occurrence of Apodemus species (see fig. 2) was found to have a slightly negative effect on hazel dormouse presence, with the chance of hazel dormouse occupancy at sites where Apodemus sp. were not present being 1.28 times higher than at sites where they were found.

Tab. 1: Recorded species, given is the number of camera sites with records during period 1 ( 85 camera sites) and period 2 (36 camera sites).

\begin{tabular}{lrr} 
Species & $\begin{array}{r}\text { Period 1 } \\
(\mathbf{N}=\mathbf{8 5})\end{array}$ & $\begin{array}{r}\text { Period 2 } \\
(\mathbf{N}=\mathbf{3 6})\end{array}$ \\
\hline Muscardinus avellanarius & 17 & 0 \\
\hline Apodemus sp. & 76 & 34 \\
\hline Apodemus agrarius & 2 & 0 \\
\hline Myodes glareolus & 30 & 13 \\
\hline Micromys minutus & 0 & 2 \\
\hline Sciurus vulgaris & 33 & 15 \\
\hline Rattus norvegicus & 28 & 6 \\
\hline Soricidae sp. & 1 & 0 \\
\hline Oryctolagus cuniculus & 1 & 0 \\
\hline Lepus europaeus & 1 & 1 \\
\hline Martes martes & 2 & 2 \\
\hline Martes foina & 0 & 1 \\
\hline Mustela putorius & 1 & 0 \\
\hline Mustela erminea & 1 & 0 \\
\hline Felis catus & 3 & 1 \\
\hline Procyon lotor & 1 & 0 \\
\hline Capreolus capreolus & 3 & 2
\end{tabular}

Correlation between hazel dormouse detection and habitat parameters shows that presence of hazel within $20 \mathrm{~m}$ of the camera site (Cramer's $V=0.366$; $p=0.012$ ), placement of the baited board directly in hazel (Cramer's $\mathrm{V}=0.587 ; \mathrm{p}<0.001)$ and a larger size of surrounding forested area (Cramer's $V=0.562 ; \mathrm{p}=0.002$ ) were heavily associated with hazel dormouse detection.

Temporal activity of the hazel dormouse shows three clear peaks: the first after dawn, the second around midnight and the third before dusk (see fig. 3).

\section{Discussion}

The temporal pattern of three activity peaks during the night suggests a similar pattern as is known in other mouse species (Hoogenboom et al. 1984). Hazel dormice returning very few times or even not at all after their first visit emphasises the profound effect a single moment of camera malfunction could have on accurate detection rates. Anomalies such as the far above average of records and returns within one area suggest possible variables and influences of importan-

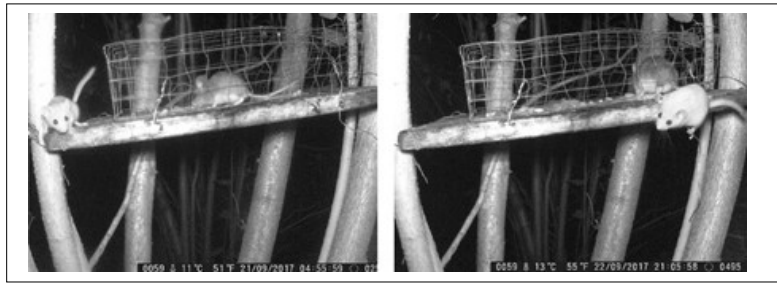

Fig. 2: Hazel dormouse climbs on the baited board while Apodemus $s p$. is feeding on the bait.

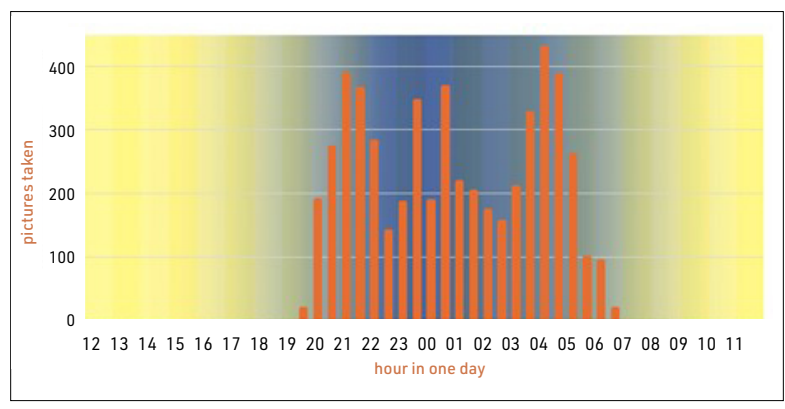

Fig. 3: Temporal presence of hazel dormice on the boards at all 17 camera sites, shown as amount of pictures taken during each 30-minute interval.

ce for the species that were not taken into account and need to be investigated further. It is uncertain whether the negative influence of Apodemus species was due to interspecies competition for resources in the area or merely increased depletion of the bait due to sheer numbers of Apodemus. Especially of interest is the one occasion where the species were documented on the board simultaneously, which occurred at one of the anomalous two sites with the overwhelming majority of dormouse records.

The importance of presence of hazel (Corylus avellana) and larger forested areas for habitat preference was reaffirmed (Juškaitis \& Šiožinytė 2008; Bright et al. 2006). The possible link of camera-/bait-placement 
within the hazel tree itself in order to in-crease detection rates is critical for further research using the same method. For presence determination on a larger scale, the commonly applied practices of using nest boxes and tubes as well as searching for nests and gnawed nuts may be more feasible and less likely to return false negatives. This is especially true when financial budget, investment of time and susceptibility to malfunction are of concern. However, camera traps have certainly proven themselves useful when more in depth analysis of ecology than mere detection of hazel dormouse presence is of interest and are invaluable for observations of interspecies interactions.

\section{Acknowledgements}

We would like to thank the Stiftung Naturschutz Schleswig-Holstein for the supply of camera-traps and the road administration (LBV-SH) for letting us make investigation on mainly their property.

\section{Authors}

\section{Nina Villing}

Nina Villing studied Animal Management at Van Hall Larenstein - University of Applied Sciences (2018: BSc). She then studied Animal Sciences at Wageningen University (2020: MSc). Currently she works as a Field Assistant at the at the Netherlands Institute of Ecology (NIOO-KNAW), Department of Animal Ecology.

\section{Lena Horst}

Lena Horst studied Animal Management at Van Hall Larenstein - University of Applied Sciences (2018: BSc).

\section{References}

Berg L, Berg A (1999) Abundance and survival of hazel dormouse Muscardinus avellanarius in temporary shrub habitat: a trapping study Annales Zoologici Fennici 36:159-165

Bright PW, Morris PA (1990) Habitat requirements of dormice Muscardinus avellanarius in relation to woodland management in Southwest England. Biol. Conserv. 54:307-326.

Bright PW, Mitchell P, Morris PA (1994) Dormouse distribution: Survey techniques, insular ecology and selection of sites for conservation. Journal of Applied Ecology 31:329-339.

Bright PW, MacPherson D (2002) Hedgerow management, dormice and biodiversity. English Nature Report 424.

Bright PW, Morris PA, Mitchell-Jones T (2006) The dormouse conservation handbook. Second edition. English Nature, Peterborough (UK).

Büchner S, Lang J, Jokisch S (2010) Monitoring der Haselmaus Muscardinus avellanarius in Hessen im Rahmen der Berichtspflicht zur FFHRichtlinie. Natur und Landschaft 8:334-339.

Foppen RPB, Verheggen LSGM, van der Meij T (2002) Handleiding meetnet hazelmuizen. Zoogdiervereniging VZZ, Arnhem.

Hoogenboom I, Daan S, Dallinga JH, Schoenmakers M (1984) Seasonal change in the daily timing of behaviour of the common vole, Microtus arvalis. Oecologia 61:18-31.

Juškaitis R, Šiožinyte V (2008) Habitat requirements of the common dormouse (Muscardinus avellanarius) and the fat dormouse (Glis glis) in mature mixed forest in Lithuania. Ekológia (Bratislava) 27:143-151.

Mills CA, Godley BJ, Hodgson DJ (2016) Take only photographs, leave only footprints: Novel applications of non-invasive survey methods for rapid detection of small, arboreal animals. PLoS ONE 11:1-12.

Schulz B, Ehlers S, Lang J, Büchner S (2012) Hazel dormice in roadside habitats. Peckiana 8:49-55

\section{Open Access}

> This article is published under the Creative Commons Attribution 4.0 International license (https://creativecommons.org/licenses/by/4.0/ deed.en). Please note that individual, appropriately marked parts of the article may be excluded from the license mentioned or may be subject to other copyright conditions. If such third party material is not under the Creative Commons license, any copying, editing or public reproduction is only permitted with the prior consent of the respective copyright owner or on the basis of relevant legal authorization regulations. 